\title{
Analysis on Promotion of Government Information Disclosure for Social Welfare
}

\author{
Li Ya \\ School of Public Management, \\ Yunnan University of Finance and Economics \\ Kunming 650221 \\ E-mail:1lyy500@163.com
}

\begin{abstract}
Government information disclosure is of great significance in terms of social welfare in that it may promote the development and improvement of social welfare. The author intends to discuss the social welfare nature of government information disclosure, based on which suggestions are proposed.
\end{abstract}

Key words - social welfare; government information disclosure

The enactment and implementation of the Regulations of the People's Republic of China on Government Information Disclosure (hereinafter referred to as the Regulations) is a great event in the administration and legal system history of China. Some even refer to it as "the third great revolution" following the Administrative Procedure Law and the Administrative License Law.

\section{GOVERNMENT INFORMATION DISCLOSURE AND SOCIAL WELFARE}

The nomological basis of government information disclosure is the right to know, which refers to the citizens' freedom and right to receive, pursue and access the information mastered by the government. Through 70 years' development, the right to know has been a basic human right which is extensively emphasized and established and protected in the form of law by all the countries in the world. One of the fundamental intents of social welfare is to secure the realization of the citizens' basic human rights; hence government information disclosure, as a legal expression of the basic human right to know in China, has natural connection to social welfare theoretically and practically.

\section{A. Government Information Disclosure Is a Kind of Social Welfare Objectively}

The 21 st century is known as a "century of information". The term "information" becomes a part of the name of an era, which means that information, like basic life necessities, has been an indispensable basic material for the people's production and life. It is safe to say that the right in relation to information has become a part of the people's life right and personal right.

Government information impacts the people's survival and their life quality, and is closely related to our sense of safety and happiness. For example, it is specified in Articles X and XI of the Regulations that the people's government of and above the county level as well as its departments shall determine the specific content of government information to be disclosed initiatively within their respective scope of responsibilities, and the following government information shall be mainly required to be disclosed: the management, use and distribution of funds and materials in relation to poverty relief, education, medical care, social security, employment promotion, emergency plan for unexpected public events, prewarning information and treatment information; environmental protection, public sanitation, production safety, food and drugs and product quality; urban-rural development and management, construction of social public welfare undertakings, land requisition and expropriation, house movement and compensation, distribution and use of subsidies; disaster relief, preferential treatment compensation, remedy and social donation. Meanwhile, such public enterprises and institutions shall be required to implement the Regulations as education, medical care and sanitation, family planning, water supply, power supply, gas supply, heat supply, environmental protection and public transport. Such information is directly related to the people's livelihood and impacts the daily life of everyone. Government information disclosure is closely related to social welfare whether directly or indirectly. Therefore, it is reasonable to consider government information disclosure as a kind of social welfare arrangement or social welfare system covering the whole country.

\section{B. Government Information Disclosure Is a Kind of Welfare for the Entire People}

Social welfare in a broad sense involves each aspect of the material and spiritual life of the entire people. It refers to the policies and measures taken as well as the welfare facilities and related services provided by the government and the society to improve the material and spiritual life of all the social members. The objects of government information in a broad sense are all the citizens and social organizations, so it may be considered a kind of welfare for the entire people. In that point, the purpose is made clear in Article I of the Regulations from the very beginning: "In order to secure the legal access of citizens, corporations and other organizations to government information, improve the transparency of government work, promote administration pursuant to law and bring the service role of government information into full play in the people's production, life and economic activities, this Regulations is hereby formulated." Instead of a privilege for the minority, government information disclosure covers the 
whole society. The government shall not only extensively publicize important information to the whole society on its own initiative in various forms, but it shall also provide convenient channels and places to access such information. Theoretically, as long as the request of the citizens is legal and the information falls in the scope of disclosure, the governments of different levels shall satisfy such request in a timely manner. Even if they are unable to provide such information directly, they shall provide help, direction and explicit notification.

\section{Government Information Disclosure Is Social Welfare of Higher Level}

Social welfare "involves such issues as what the society relies to help the people live happily, what system and policy the society uses to ensure their happy life and how social wealth, opportunities and various materials are distributed among the social members." In the 1990s, the US scholars proposed the idea of "information welfare society" for the first time. Subsequently the Korean scholars defined "the right of information welfare": "In the times of information, all the social members shall be secured with equal right to access information, obtain useful information and enjoy information autonomously. In other words, with the development of the information society, as a citizens' right, the citizens shall be secured with the right to access information media, the right to receive information service, the right to use information and the right of information welfare." We should say that information welfare is the latest development and higher-level representation of social welfare.

Firstly, government information disclosure is a resource distribution mechanism. Information is a resource which means wealth. Reasonable distribution of resources has been one of the key points for the social welfare system of each country. Therefore, government information disclosure system may be considered a way of public information resources, in particular, the citizens' right to know, right of involvement, right of expression and right of supervision secured by the system are for the purpose of more reasonable allocation of such public resources.

Secondly, government information disclosure is an opportunity equality mechanism. One of the modern representations of wealth and opportunity is information. The time, quality and degree of information access and the ability to use information have been critical elements determining the personal business success and national prosperity. Each person, from birth to death and from school to employment, is faced with the issue of opportunity equality, while various social organizations under the market economy system hope to have a macro-environment of fair competition. Looking back, we find that the social unequal phenomenon revealed by media are fundamentally caused by information insufficiency, asymmetry and in accuracy. Government information disclosure, to a large extent, is determined in response to the public voice for an equal society and the demand of market economy.

Thirdly, government information disclosure is a demand satisfaction mechanism. People are owners of the country and to know about various government behaviors representing their interests is the basic respect for them, which is the main reason why the right to know becomes an indispensable part of the human right. If the people may get involved in the political process of the country with this opportunity and make their claim influential and even realized to promote the national political process with their own forces, it is the greatest self-realization for each citizen of sense of social responsibility.

And finally, government information is a democratic involvement mechanism. Democracy is the greatest social welfare. Public involvement is one of the main ways to realize democracy. For involvement, the first should be to know, based on which opinions are proposed, expressed and realized. Therefore, accessing government information is a necessary condition for the citizens to realize democratic involvement. Without "knowing information", it is impossible to "know politics", hence government information disclosure securing the right to know becomes the basic precondition to realize the greatest social welfare of democracy.

\section{GOVERNMENT INFORMATION DISCLOSURE AND INFORMATION WEAK GROUPS}

The objects of social welfare in a narrow sense are weak groups of the society. Amartya Sen, the Nobel Prize Winner in 1998 , holds that the true meaning of poverty is the poverty of population in the ability and opportunities of creating income; poverty means that the population in poverty is in lack of the ability to obtain and enjoy a normal life.

In the times of information, almost all the social activities cannot go without information and communication means. Involvement would be impossible without information and communication, which leads to the loss of the opportunity to generate income and improve life. That results in a kind of new poverty-information poverty. In reality, although different weak groups need improve different abilities and get different helps, weak groups tend to be "information weak groups" in general, with the characteristic of "information poverty". In other words, they lack basic means, equipment and ability to access and use information, with the occupation of information resources significantly less than other groups, which causes further economic and spiritual poverty. In this way a vicious circle hard to overcome is formed.

Government information disclosure is one of the feasible ways for weak groups to access information concerning survival and development and to get rid of information poverty, thus to improve the condition of material and mental poverty. It mainly includes two reasons:

Firstly, government information disclosure helps weak groups get basic security for survival. In the society most of the helped or supported know nothing about the social welfare policy of the government. They have no idea about the channels and ways to seek for help or their rights and interests of social welfare. The personal and family tragedy of various weak groups is always accompanied with the ignorance resulting from information poverty. Government is the primary principal of social welfare, the formulator of social welfare laws, regulations and policies, the main provider of public products and the manager for the operation of social welfare system. The government masters a majority of the social welfare resources and information. For weak groups, it is directly related to their survival whether they can effectively 
get such information to be helped or supported, or be taken into the welfare system through information channels.

And secondly, government information may help weak groups get the opportunity to improve their state of survival. It is the social welfare obligation of the government to provide weak groups with various necessary opportunities to improve their state of survival. The massive information mastered by the government will definitely include the information of various kinds required to help weak groups improve their life. The key is whether such information can be effectively developed and utilized and publicized to the society in a timely manner. On the level of practice, government information disclosure has shown its power in serving weak groups. For example, the information released by the government for farmer workers in relation to labor employment and agricultural product supply and demand, the medical care information released for the aged, and right maintaining law popularization publicity for the women suffering from family violence and the social security information for the unemployed in urban areas ... such information irrelevant to the common people is probably a ray of morning twilight for the weak groups to get rid of their present situation of poverty and return to normal life. Government information disclosure is an opportunity. It is an opportunity for weak groups to start a new life as well as an opportunity for the government to recreate its image, transform its functions and serve the people down to earth.

\section{Approach to Promoting Social Welfare With GOVERNMENT INFORMATION DISCLOSURE}

\section{A. Emphasize the Issue of "Information Gap"}

"Information gap" is represented in multiple forms, in China mainly represented as the difference between developed regions and underdeveloped regions, urban areas and rural areas, and among different classes or groups in terms of the right and ability to access and use information. As information and economy are closely connected, such difference will not only cause inequality in information access, but it will also cause a series gaps in such aspects as economy, politics, culture and life quality. "Its direct consequences are social structure unbalance, right unbalance, wealth gap, disorder and poor development, causing social conflicts." Government information disclosure relieves the issue of information gap to some degree. Economic position is the primary cause for information gap, while the public welfare, open and equal nature of government information eliminates the difference in information capacity resulting from economic difference. It is just a relief instead of a real solution, but it may give us several implications.

Implication I: The presence of information gap has already caused social inequality, which is a new destructive power for the social welfare system. Information gap will not disappear naturally and it will worsen if left on its own, causing a series of consequences hard to control.

Implication II: It is the responsibility of the government to eliminate various social inequalities. In the campaign of eliminating digital gap, the government is not only the commander, but also a fighter on the frontline. The purpose of various public welfare or inexpensive means of information access led by government is to resist the inequality of social resource distribution by the means of social welfare.

Implication III: The issue of digital gap is extremely complicated, which requires comprehensive means of treatment, such as improving the social informatization level of underdeveloped regions, reducing the cost of information access, helping the public establish the sense of information, improving the public skills of information and emphasizing information poverty relief.

Implication IV: The informatization of the government itself is critical, which includes both the software and hardware informatization construction of the government and the informatization construction of the government officials' minds.

Implication V: Strengthen the construction and service of such public culture and information institutions as libraries and archives to bring their role of regional information center into play, with priority given to the security of basic information demand of the local public.

\section{B. Cluster Social Forces to Provide Broader and Simpler Channels to Obtain Government Information}

Presently there are to primary approaches of government information disclosure in China: one is the websites of governments of different levels and the other is the government information consultation center. For the common social public, the two approaches may basically solve the issue of access to government information. However, the two approaches obviously have the problem of incomplete coverage: no attention is paid to the groups who cannot use computer and internet due to economic conditions or use ability, the groups of low education level are ignored and the attention to the disabled is insufficient. Although it is required in the Regulations that the governments of different levels disclose government information in various ways convenient for the public and it is particularly specified that necessary help should be provided for the citizens of difficulty in reading or with audio visual disorders, "convenience to know" is not realized extensively due to insufficient emphasis or inability of the government. Therefore, various communication channels should be sought for in addition to traditional information channels to communicate government information to the groups in urgent need of such information welfare.

\section{Strengthen the Development and Utilization of Government Information Resources}

Government controls the resource treasury of government information, while most of such precious resources are in closure and sleep. With low degree of publicity and sharing, such information is neither known nor used by the people. The presence of a large number of information isolated islands makes it difficult to bring the basic information value of government information resource into play, not to mention its social welfare value. To change the situation, the government should enhance information resource development and utilization, and public archives and libraries should also become a leading power to join in the work. Public archives and libraries are not only statutory government information reference center, but also the most specialized information development and utilization departments in a region. As public cultural undertaking units, they should gain achievements in terms of effective development and utilization of government 
information to serve the society with their specialty and to satisfy the public demand for social welfare with public information services and information products.

\section{Help Weak Groups Improve the Conditions for Access to Information}

Helping weak groups is the center of social welfare work, and government information disclosure should also emphasize and provide great support for weak groups. Instead of being limited to finite material support, modern social welfare has turned to the way led by ability improvement. Weak groups tend to lack the abilities and conditions to adapt to the society due to various reasons which naturally include the skills of information access and utilization. "Information ability endowment" for them is a necessary means. With reliable source, government information is easy to access and the content of such information is greatly helpful for weak groups. Starting with accessing government information may help them master the skills of social life, return to the society and enjoy the social welfare they deserve.

Weak groups require different information abilities, some in lack of necessary information equipment due to economic reasons, some unable to use information means due to physiological reasons and others unable to effectively understand information due to education level. That requires that the way of information ability endowment must be individualized according to their respective characteristics and information demands. However, the government obviously has no such conditions and capacity to serve individuals, and actually it is not necessary for the government to do so. The advantages of government are to direct, make overall arrangement of and mobilize social forces. In particular, under the background of "micro-environment and macro-society", only mobilizing and relying on the social forces is the solution to the issue.

\section{REFERENCES}

[1] Xiang Zuoqun. Research on Government Information Disclosure System. Beijing: Intellectual Property Publishing House. 2007.

[2] Qian Ning et al. Ideology on Modern Social Welfare. Beijing: Higher Education Press. 2006.

[3] Robert Alan Dahl. Translated by Li Boguang and Lin Meng. On Democracy. Beijing: the Commercial Press. 1999.

[4] Wang Wanhua et al. Research on Right to Know and Government Information Disclosure System. Beijing: China University of Political Science and Law Press. 2013.

[5] Li Guangyu. Textbook for Judicial Interpretation of Government Information Disclosure. Beijing: Law Press China. 2011.

[6] Zhu Yougang. Research on Government Information Disclosure from the Perspective of Service-Oriented Government. Doctoral Dissertation of Shandong University. 2012.

[7] Wang Fang. Social Information Welfare and the Approach to Realization, in Book Information Work. 2009 (18).

[8] Sun Guangde and Dong Keyong et al. Overview of Social Security. Beijing: China Renmin University Press. 2004. 